\title{
La representación de la mujer inmigrante en la prensa nacional ${ }^{1}$
}

\author{
Erika Masanet Ripoll \\ Carolina Ripoll Arcacia \\ Universidad de Alicante
}

\section{Resumen}

El presente trabajo constituye un estudio de carácter exploratorio sobre las representaciones y las imágenes sociales que transmite la prensa española acerca de la mujer inmigrante. A través de un análisis cualitativo de las noticias aparecidas durante el 2004 en los tres diarios nacionales más importantes (El País, El Mundo y el $A B C$ ), se indaga en las temáticas y en las situaciones más relevantes en las que aparece, su relación con otros grupos o actores sociales, los principales roles que desempeña en la noticia y el tipo de protagonismo que ejerce en las noticias. El análisis de los datos muestra la invisibilidad de la mujer inmigrante y su representación marginal y vulnerable en la prensa.

Palabras clave: inmigración femenina, prensa escrita, imágenes sociales, estereotipos.

\section{Abstract. The representation of immigrant women in the national press}

The aim of this investigation is to explore the social representations and images that the Spanish press transmits about immigrant women. Inquiring the news appeared in 2004 in the most important national newspapers (El País, El Mundo and $A B C$ ) and using a qualitative analysis, this research brings to light the most frequent clichés and social situations of these women in the press, their relations with other social groups, their main roles and their prominence in news. The results show the invisibility of immigrant women and their marginal and vulnerable representation in the press.

Key words: female immigration, written press, social images, stereotypes.

\author{
Sumario \\ Introducción \\ 3. Resultados obtenidos \\ 1. Antecedentes y estado de la cuestión \\ Conclusiones \\ 2. Metodología Referencias bibliográficas
}

1. El presente artículo ha sido posible gracias al proyecto La representación de la mujer inmigrante en la prensa nacional, financiado por el Centro de Estudios de la Mujer (CEM), de la Universidad de Alicante, en el 2005. Las autoras agradecen los comentarios y las sugerencias del profesor Clemente Penalva Verdú de la UA. 


\section{Introducción}

En la actualidad, los medios de comunicación se han convertido en uno de los principales vehículos de construcción y transmisión de estereotipos culturales y de identidad cultural, porque, por un lado, facilitan la comparación con otros grupos culturalmente definidos y, por otro, porque se basan en la transmisión globalizada de una única identidad cultural dominante (la occidental) por parte de los principales grupos mediáticos. De este modo, el papel que los expertos atribuyen a los medios es el de constructores de la realidad social mediante las prácticas de selección y tratamiento de las noticias (González y otros, 2004).

Tal y como afirman M. McCombs y D. Evatt (1995: 31), «al prestar atención a ciertos aspectos, a expensas de otros, y al sugerir ciertas soluciones o respuestas en lugar de otras, los mensajes de los medios de difusión influyen en algo más que en los temas, influyen en el modo en que la gente piensa sobre esos temas». Por tanto, los medios influyen en la percepción de la opinión pública sobre un determinado tema, al dotarlo de significado. En este sentido, desde diferentes ámbitos (organizaciones, instituciones, etc.) preocupa la manera en que los medios de comunicación construyen determinadas representaciones o imágenes sociales de la inmigración.

El presente trabajo tiene como objetivo principal analizar el tratamiento que los medios de comunicación, y más concretamente la prensa escrita, realiza sobre la mujer inmigrante ${ }^{2}$. Es decir, se trata de investigar, de manera exploratoria, la imagen que proyecta la prensa escrita sobre este tema. El estudio se ha llevado a cabo mediante un análisis cualitativo de las noticias aparecidas en los tres principales periódicos nacionales de nuestro país (El País, $A B C$ y El Mundo) durante el 2004.

En nuestro trabajo partimos de tres hipótesis principales. En primer lugar, la prensa nacional sobredimensiona la presencia de ciertos grupos nacionales de mujeres inmigrantes, al tiempo que infravalora otras nacionalidades. En segundo lugar, los medios de comunicación transmiten una imagen negativa y estereotipada de la mujer inmigrante, al aparecer mayoritariamente en situaciones negativas o violentas (redes de prostitución ilegal, malos tratos, etc.). En tercer lugar, el papel que ejerce la mujer inmigrante en la prensa es básicamente el de víctima. De este modo, las mujeres inmigrantes son presentadas como mujeres objeto de la acción del hombre, dependientes, subordinadas y sumisas.

El artículo está estructurado en tres apartados. En primer lugar, se ofrece un breve resumen del estado de la cuestión sobre los estudios de género y migración, así como de la literatura sobre medios de comunicación y migración y la relación entre migración, género y medios de comunicación. A continuación,

2. La definición de mujer inmigrante que tomamos para nuestro estudio es la siguiente: «La mujer procedente de países periféricos que protagoniza migraciones laborales hacia los países del Centro, con independencia de cuál sea su estatuto jurídico (irregular, regular, nacionalizada)» (Parella, 2003: 11). 
pasamos a explicitar la metodología llevada a cabo en el estudio. En tercer lugar, se presenta una síntesis de los principales resultados obtenidos del análisis cualitativo sobre las noticias de mujeres inmigrantes en la prensa nacional.

\section{Antecedentes y estado de la cuestión}

En los últimos años asistimos a un aumento en la feminización de la inmigración extracomunitaria en nuestro país, de tal modo que constituye el $47 \%$ del total de población extranjera, según datos del padrón municipal de habitantes del 2004 realizado por el INE ${ }^{3}$. La composición de las mujeres extracomunitarias según nacionalidad indica un predominio de las mujeres ecuatorianas (con un 17\% del total femenino), seguidas de las marroquíes y las colombianas (ambas con un 9,9 del total femenino). A continuación se situarían las mujeres rumanas, con un porcentaje del 6,5\% del total femenino (INE, 2004).

En los estudios sobre género y migración realizados en nuestro país ${ }^{4}$, se observa cómo este tema ha sufrido un retraso en comparación con las publicaciones sobre la inmigración en general. Además, en los primeros estudios sobre migración extranjera, se obvia la importancia del proceso migratorio autónomo femenino. De este modo, las primeras investigaciones sobre la mujer inmigrante tratan principalmente los temas del reagrupamiento familiar, el papel del género en los modelos de asentamiento y la segunda generación. No ha sido hasta hace poco, cuando la mujer ha sido considerada como actor migratorio y la variable género se ha convertido en un factor de análisis en sí mismo, tomándola en cuenta en el análisis de las trayectorias y los proyectos migratorios.

En la cuestión del género en las migraciones, la temática predominante en los estudios es la relacionada con el trabajo que desempeña la mujer inmigrante en nuestra sociedad. Principalmente, el foco de atención ha sido el servicio doméstico y personal, sector de trabajo que ocupan mayoritariamente las mujeres inmigrantes. La creciente situación de mujeres que vienen solas a trabajar y las duras condiciones laborales que caracterizan a la ocupación femenina inmigrante, hacen que este campo de estudio sea prolífico en nuestro país (Colectivo Ioé, 1991a, 1991b y 2001; Martínez Veiga, 1995; Izquierdo, 1996; Escrivá y Romero, 1997; Escrivá, 2000; Catarina y Oso, 2000; Bonelli, y Ulloa, 2001; Parella, 2000 y 2003, etc.). Por otro lado, la problemática relacionada con la prostitución y su relación con las redes de tráfico ilegal está captando cada vez más la atención de los investigadores y las investigadoras (Carmona, 2000; Bonelli, y Ulloa, 2001).

3. Hacemos referencia a los datos estadísticos del 2004 porque nuestro análisis de prensa abarca el ámbito temporal del 2004.

4. Para la revisión del estado de la cuestión sobre género y migración, nos hemos basado en el artículo de Gemma Aubarell «Una propuesta de recorrido bibliográfico por las migraciones femeninas en España», 2000. 
El Anuario de Estadísticas Laborales (2004) indica que las mujeres presentan una alta concentración en el sector servicios: la hostelería (21\%) y el servicio doméstico (18\%). Esta última cifra relativa al servicio doméstico está infravalorada, puesto que existe un importante número de mujeres irregulares que trabajan sin contrato de trabajo en el servicio doméstico y que, por tanto, no están contabilizadas en las estadísticas. A pesar del ya reducido abanico de actividades en que puede emplearse la población inmigrante, los trabajadores extranjeros masculinos presentan una mayor variedad de posibilidades en comparación con las mujeres trabajadoras extranjeras, las cuales quedan relegadas casi exclusivamente a un «nicho laboral» concreto: los servicios de proximidad, lo cual indicaría claramente una feminización del sector doméstico (Parella, 2000: 278-279).

De las investigaciones realizadas sobre el tratamiento de la inmigración en los medios de comunicación (Bodas y Dragoevich, 1994; Buisef, 1994; Roiz, 1994; Del Álamo, 1997; Estupiñán, 1997; Peñamarín, 1997; Rodrigo y Martínez, 1997; Rizo, 2001; Abella, 2002; Bañón, 2002; Siurana, 2004; etc.), se desprende que existe cierta unanimidad en el discurso de la inmigración. De este modo, los medios de comunicación transmiten una imagen negativa y estereotipada del inmigrante, como también contribuyen a definir la inmigración como algo problemático y conflictivo para el país. Según A. M. Bañón (2002: 283), «tanto las aproximaciones cuantitativas como cualitativas han puesto de manifiesto la tendenciosidad informativa de numerosos textos periodísticos referidos a la inmigración, así como las estrategias sociocomunicativas y textuales en las que tal tendenciosidad se observa». Se relaciona sobre todo a la inmigración con aspectos conflictivos o males sociales (delincuencia, inseguridad ciudadana, tráfico, venta y consumo de drogas, prostitución...) o con sentimientos caritativos hacia estas personas, de tal modo que se potencia el miedo o la compasión hacia ellas. Asimismo, hay una presencia exagerada de fuentes oficiales (institucionales o policiales), al tiempo que se da una escasa presencia de otras fuentes procedentes de ONG, de asociaciones de inmigrantes. Raramente son los propios inmigrantes los que participan en las informaciones que les afectan, por lo cual carecen de voz como protagonistas. De igual modo, los temas relativos a la familia, a la vida cotidiana, a la vivienda, a las condiciones de trabajo, a la participación social, a los derechos políticos y sociales, son prácticamente inexistentes. No se recogen apenas casos de integración o convivencia, ni de solidaridad con los inmigrantes y las inmigrantes.

Los estudios realizados en nuestro país sobre la imagen de la mujer inmigrante en los medios de comunicación son escasos y casi inexistentes. Cabe señalar, en todo caso, la aportación de Rosabel Argote (2003) sobre el análisis de la representación de la mujer inmigrante en el cine español. La conclusión a la que llega la autora es que la mujer inmigrante tiene la categoría de objeto sin voz del sujeto, y éste último suele ser un hombre. De los personajes de estas películas, «la mujer inmigrante es la peor parada. No tiene voz; es prostituta en la mayoría de los casos; suele ser pícara malintencionada y su presencia en el filme se justifica como un elemento desestabilizador que narrati- 
vamente hay que aniquilar o domesticar para una recuperación del equilibrio inicial» (Argote, 2003: 121).

¿Qué conocemos a través de la prensa de las mujeres inmigrantes? Los dos estudios encontrados sobre el tratamiento de la prensa escrita española sobre las mujeres inmigrantes dejan entrever la insuficiente información que aportan los periódicos al respecto, además de la distorsión y la poca adecuación a la realidad del fenómeno. Uno es el estudio realizado por Fabiola Calvo (2001), en el cual también analiza las noticias aparecidas en El País, El Mundo y ABC, además de La Voz de Galicia. Según las informaciones obtenidas del análisis de este estudio, la imagen predominante que trasladan los medios de comunicación sobre las mujeres inmigrantes es que se trata de mujeres víctimas engañadas por redes mafiosas y, además, señalan a estas mafias como las únicas responsables de la explotación que sufren muchas de estas mujeres. De este modo, se obvia la responsabilidad que tienen otros actores sociales y la sociedad en general en la situación de estas mujeres, al tiempo que ocultan las verdaderas causas de esta explotación y las posibles soluciones para evitar estos abusos (Calvo, 2001: 63-64). Por su parte, el estudio realizado por Clara Pérez (2003) señala la invisibilidad de la mujer inmigrante respecto del hombre inmigrante a través del uso del masculino genérico «los inmigrantes». Esta invisibilidad también se percibe en el hecho de que, en los medios de comunicación, se presenten cifras sobre inmigración sin desagregar por sexo. Asimismo, los temas más vinculados a las mujeres inmigrantes son la problemática del velo, los matrimonios forzados por las familias o las mutilaciones genitales. Las inmigrantes como trabajadoras prácticamente no existen, y si aparecen son como cuidadoras domésticas, prostitutas (secuestradas y traficadas) o bajo la sospecha de que han inmigrado para casarse con un hombre español que las mantenga.

A la luz de la exploración anterior, podemos observar cómo la escasez de investigaciones que analicen el tratamiento de los medios de comunicación sobre la mujer inmigrante, hace que el presente trabajo de investigación constituya un estudio innovador y original que contribuye a aumentar el conocimiento en la literatura sobre género y migración en España. Asimismo, esta investigación puede constituir un interesante punto de partida en los estudios sobre las diferencias de género en el tratamiento de la inmigración en los medios de comunicación, así como sus efectos en la opinión pública.

\section{Metodología}

La metodología empleada en nuestro estudio ha sido esencialmente de corte cualitativo, la cual se presenta como la más idónea para abordar un estudio de tipo exploratorio como es el nuestro. El tipo de muestreo utilizado, por tanto, ha sido el no probabilístico intencional, en el cual se pueden realizar generalizaciones a partir de la inferencia lógica, de ahí que la muestra en la metodología cualitativa no sea representativa estadísticamente, sino que se trata de una muestra teórica o socioestructural del objeto de estudio que se quiere estudiar. 
El muestreo no probabilístico intencional viene definido por tres criterios que aseguran la diversidad de discursos, con lo que se cumple la fiabilidad del estudio. De este modo, la diversidad de la muestra se ha establecido en términos espaciales, temporales y formales. En primer lugar, la diversidad espacial se cumple por la utilización de tres periódicos para la selección de la muestra (El País, El Mundo y $A B C$ ). Las razones de la elección de estos tres periódicos radica en que son los de mayor difusión en el ámbito nacional y en que, además, abarcan la mayor parte del espectro ideológico de la opinión pública española. En segundo lugar, la muestra también sigue el criterio de la diversidad temporal, al seleccionar la información sobre la mujer inmigrante en una determinada época: desde el 1 de enero del 2004 hasta el 31 de diciembre del 2004, abarcando así toda la estacionalidad posible. La elección del año 2004 reside en el hecho de que se trató de un año de intenso debate en torno al tema de la violencia contra la mujer, que desembocó en la Ley Integral contra la violencia de género, aprobada en octubre de dicho año. En tercer lugar, la diversidad de formato o género periodístico se cumple porque abarca todos los estilos y las formas de expresión de la comunicación periodística (crónica, reportaje y artículos de opinión). Asimismo, el muestreo no probabilístico también viene definido por el principio de saturación de la información o saturación teórica. El punto de saturación se alcanza cuando la información recogida resulta redundante y la adopción de nuevas unidades no aportaría novedades a los objetivos de investigación. A partir de estos criterios o principios, se ha procedido a la extracción de la muestra o de los documentos a analizar, que en total ha sido de 45 noticias centradas en la mujer inmigrante. En este sentido, debemos señalar el gran esfuerzo que supuso la obtención del corpus textual para el análisis, lo que evidencia la invisibilidad de la mujer inmigrante en la prensa nacional.

Finalmente, cabe indicar que la reducción de datos consistió en un proceso de postcodificación para el establecimiento de categorías relevantes y sus conexiones, con el fin de encontrar la estructura de los datos. Estas categorías están presentes en los resultados de la investigación que se muestran a continuación.

\section{Resultados obtenidos}

\subsection{La nacionalidad de la mujer inmigrante en prensa}

Como ya apuntamos anteriormente, la presencia de la mujer inmigrante en la prensa nacional es escasa, sobre todo en relación con las informaciones sobre el colectivo inmigrante en general, en las que el hombre inmigrante aparece sobrerrepresentado. Esto evidencia la invisibilidad que sufre la mujer inmigrante en nuestra sociedad y que tiene su reflejo en la prensa escrita.

En las noticias analizadas se aprecia una tendencia a la repetición de las mismas nacionalidades, de tal modo que hay un mayor protagonismo de unas en detrimento de otras. Como puede observarse en el cuadro 1, destaca la 
Cuadro 1. Noticias por nacionalidad en El Mundo, $A B C$ y El Pais

\begin{tabular}{lc}
\hline Nacionalidad/ grupo de países & No de $^{5}$ \\
\hline Rumana & 13 \\
General $^{7}$ & 9 \\
Ecuatoriana & \\
Dominicana & 5 \\
Nigeriana & 4 \\
Rusa & 4 \\
Europa del Este & 3 \\
Marroquí & 2 \\
Argelina & 2 \\
Brasileña & 1 \\
China & 1 \\
Colombiana & 1 \\
Paraguaya & 1 \\
Peruana & 1 \\
Serbocroata & 1 \\
& 1 \\
\hline
\end{tabular}

nacionalidad rumana, por ser la de mayor frecuencia de aparición en los tres periódicos.

Comparando este hecho con las estadísticas oficiales expuestas anteriormente, podemos observar cómo los medios de comunicación no muestran fielmente la realidad del fenómeno. Así, la nacionalidad rumana aparece sobrerrepresentada en la prensa nacional, puesto que ocupa el cuarto lugar del total de mujeres inmigrantes en nuestro país y en la prensa ocuparía el primero. Del mismo modo, el colectivo de las marroquíes y las colombianas aparece muy poco en las noticias, cuando estos dos colectivos suponen un porcentaje importante de las mujeres inmigrantes en nuestro país (ocupan el segundo y el tercero lugar, respectivamente, del total de mujeres inmigrantes, con unos porcentajes casi idénticos). Por colectivos, los datos del padrón del 2004 nos muestran cómo el colectivo de mujeres de Europa del Este y el de africanas representan porcentajes muy similares $(13,44$ y 13,19 , respectivamente) respecto del total de mujeres residentes en nuestro país. Este dato contrasta, por tanto, con la infrarrepresentación del grupo de africanas en la prensa nacional.

5. Se han nombrado las categorías tal y como aparecen en las noticias.

6. Cuando en una misma noticia aparecen varias nacionalidades, éstas se han incluido en cada una de las categorías a las que hace referencia.

7. En la categoría "general» hemos incluido las noticias que hablan de las mujeres inmigrantes en general, sin nombrar ninguna nacionalidad en particular. 
Por tanto, la tendencia en la prensa nacional es a hablar de mujeres oriundas de Europa del Este y de Latinoamérica, lo que trasmitiría la imagen errónea de que la mayoría de las inmigrantes proceden de estos países, creándose así estereotipos. Por otro lado, del grupo de mujeres africanas apenas hay noticias sobre ellas, es como si no existieran en nuestra sociedad.

\subsection{La relación de la mujer inmigrante con otros grupos o actores sociales}

\section{La relación con el varón}

Es importante analizar la relación que tienen las mujeres inmigrantes con otras personas o colectivos. A la vista de las noticias, las mujeres normalmente se relacionan con hombres y éstos son, en la mayoría de los casos, sus maltratadores, proxenetas, asesinos o violadores casi siempre de la misma nacionalidad. Es decir, en la mayoría de los casos, la mujer es la víctima y el hombre es el verdugo. Incluso cuando no se da esta circunstancia, normalmente se suele citar el estado civil de la mujer, refiriéndose a ésta con respecto a su vinculación o no a un varón. La mujer, por tanto, aparece en la mayoría de los casos vinculada al varón.

Si nos detenemos un poco en la figura del hombre agresor, observamos cómo en la gran mayoría de los casos el agresor es inmigrante, sólo en alguna ocasión es español. De este modo, se estaría dando una imagen del hombre inmigrante agresiva e incluso delictiva y de la mujer como víctima de estas acciones, incapaz de defenderse, que lleva una vida marginal o que incluso llega a perder la vida.

\section{Relación con la población autóctona}

En las noticias analizadas, las mujeres inmigrantes apenas tienen relación con la población autóctona. En un número mínimo de casos, se trata de vecinos testigos de los malos tratos o del asesinato. De este modo, la relación de las inmigrantes con la población autóctona o sociedad de acogida se reduce exclusivamente a la Administración, especialmente a los miembros de los cuerpos de Seguridad del Estado: policía nacional y local, guardia civil, Brigada Provincial de Extranjería y Documentación del Cuerpo Nacional de Policía, Unidad contra las Redes de Inmigración de la Policía Nacional, Mossos de Esquadra, Grupo de Menores de la Policía, agentes de la Unidad contra las Redes de Inmigración y Falsificación... Esto da pie a la asociación de la inmigración con delincuencia y actos delictivos por parte de la opinión pública española, lo que contribuye a transmitir una imagen negativa de las inmigrantes.

Del mismo modo, se habla también de ingreso en prisiones y, por tanto, de miembros pertenecientes a la justicia española: Ministerio de Justicia, Tribunal Supremo, protección de menores, juzgados, Audiencia Provincial, Audiencia Nacional, Fiscalía de Menores. También aparecen centros sanitarios, como, por ejemplo: Hospital Fundación de Alcorcón, Hospital Puerta de Hierro, Centro de Salud de Fraga, Conselleria de Sanidad, Red Centinela de la Conselleria de Sanidad. Otros tipos de administración que se mencio- 
nan son las siguientes: Consejería de Bienestar Social de Madrid, Ministerio del Interior, Comisión Española de Ayuda al Refugiado...

Esto da una idea del contexto en que se desenvuelven las mujeres inmigrantes, siempre relacionadas con asuntos delictivos, juicios, estancias hospitalarias... Además, aparecen frecuentemente citadas fuentes de carácter judicial (policía, comisaría, juzgados, extranjería, etc.) que atestiguan y dan fe de la acción que se desarrolla en la noticia. Esto denota una necesidad de legitimar la acción delictiva y/o la situación de víctima a través de alguna autoridad española.

\subsection{La imagen de la mujer inmigrante en las noticias}

La principal temática sobre la mujer inmigrante en la prensa nacional gira en torno a las redes de prostitución y el tráfico de seres humanos. Especialmente, las noticias hacen alusión a mujeres que, en su país de origen o en España, son engañadas y/o secuestradas para introducirlas en el mundo de la prostitución.

Titular de $A B C, 31-01-2004:$ «Desarticulan en Málaga una red de tráfico ilegal de mujeres del Este».

Titular de El País, 13-11-2004: «Una mujer se tira por una ventana y destapa dos redes de prostitución».

Titular de $A B C, 8-02-2004:$ «La explotación sexual mueve en España 12.000 millones de euros cada año». Subtítulo: "Un tercio de las redes de inmigrantes desarticuladas son de prostitución». Entradilla: «Casi el 70 por ciento de las mujeres son extranjeras».

Mediante este tipo de noticias, se transmite una imagen bastante negativa y poco real, basada en la idea de que las mujeres inmigrantes trabajan principalmente en la prostitución, como «trabajadoras sexuales». Imagen que contrasta con la importante dimensión que ha adquirido en nuestro país el trabajo de la mujer inmigrante en el sector doméstico y personal, y que beneficia tanto a las mujeres autóctonas (que pueden desempeñar mejor sus trabajos profesionales y ascender socialmente) como al Estado, al disminuir la presión en las ayudas públicas sociales.

Otro tema recurrente son las informaciones acerca de mujeres inmigrantes muertas a manos del compañero o del ex compañero sentimental, es decir, la violencia de género. Las víctimas del $11-\mathrm{M}^{8}$, el aborto, la expulsión del país, la violación, el abandono de hijos, la falsificación de documentos, etc., aun-

8. En este tipo de noticias se percibe un salto cualitativo en el tratamiento que hace la prensa sobre el colectivo inmigrante en general, más cercano a la situación de las mujeres inmigrantes. De este modo, las inmigrantes adquieren voz y protagonismo en estas noticias. Ellas mismas son las que cuentan cómo les ha afectado a sus vidas el atentado terrorista de Madrid. Además, es uno de los pocos casos en el que a las mujeres se las trata como trabajadoras en los servicios de proximidad. 
que, en menor medida, serían otras cuestiones vinculadas a la mujer inmigrante en prensa.

Como podemos observar, la temática dominante sobre la mujer inmigrante en prensa tiene una connotación claramente negativa. Negatividad proyectada por tres razones: porque aparece la mujer como víctima, porque comete algún acto delictivo o porque el tono de la noticia crea alarma a causa de algún motivo. En cambio, las noticias consideradas positivas, es decir, aquéllas en las que se ofrece información sobre su contribución positiva a la sociedad (económica, demográfica, social o cultural), los temas relacionados con solidaridad hacia las mujeres inmigrantes y los aspectos de integración social, etc. son una minoría en la prensa nacional.

Son muy significativos los términos empleados en los titulares de las noticias. De este modo, si se da una abundancia de vocablos peyorativos, se dará una imagen negativa del tema sobre el que se está hablando. Como muestra de los verbos principales utilizados en las noticias sobre la mujer inmigrante, podemos subrayar: apalear, denegar, explotar, violar, mendigar, arrestar, obligar, abusar, fallecer, traficar, abandonar, degollar, prostituirse... Como vemos, son verbos relacionados con violencia, delincuencia y marginación, todos ellos con una connotación negativa clara. Así es tal y como se verá a la mujer inmigrante, relacionada con la violencia, la delincuencia y la marginación.

Si nos fijamos en los sustantivos y en los adjetivos, los términos más empleados son los siguientes: proxenetas, prostitución, prisión, mutilada, detenidas, banda, explotación sexual, pateras, dolor, indignación, suicidio, sin papeles. Queda muy claro el tipo de noticias en las que aparecen las mujeres inmigrantes y, por tanto, el tipo de imagen que se tendrá de ellas por parte del lector que, como hemos dicho, es de marginación y delincuencia en la mayoría de los casos.

Por otro lado, los calificativos con los que nombran a la mujer inmigrante son diversos, pero a lo que más se alude es a la nacionalidad de la mujer. Así, en algunas ocasiones, se la nombra con el gentilicio: «una nigeriana» (El Mundo, 5-03-2004) y, en otras ocasiones, se manifiesta su condición de ciudadana: «ciudadanas chinas» (El Mundo, 18-04-2004), "ciudadana rumana» (El Mundo, 2-02-2004). Este último caso nos parece más correcto, sin embargo no es lo más utilizado, puesto que lo que más abunda es la condición de mujer con el gentilicio del país de procedencia.

Finalizamos este apartado observando la relación entre la nacionalidad y los temas para indagar en la creación de estereotipos a través de la prensa. De lo que se desprende en este aspecto analizado es que no se puede concluir que exista una relación directa entre nacionalidad y temática, puesto que a cada nacionalidad se le suele atribuir más de un tema. Sin embargo, sí se perciben ciertas tendencias que favorecen a crear estereotipos. Así, las mujeres rumanas en general aparecen vinculadas con el tema de la prostitución y las redes de explotación sexual. Debido a la gran cantidad de noticias referidas a la prostitución de mujeres rumanas y a las mafias de esta misma nacionalidad, se puede llegar a percibir una relación directa entre ciudadanos de este país y las redes de inmigración ilegal, además de favorecer una visión de marginalidad 
de las mujeres rumanas. Por ejemplo, en El País del 13 de noviembre de 2004, podemos leer: «Una mujer rumana, que llegó a España con falsas promesas de trabajo y extorsionada para ser prostituida [...]». En otra noticia de El País del 10 de agosto de 2004, encontramos: «El intento de suicidio de una joven rumana, que ingirió una gran cantidad de lejía, permitió el domingo una nueva desarticulación de una banda de explotación sexual [...]». En un titular de El Mundo del 26 de febrero de 2004, aparece: «Arrestado un portero de un club de alterne de Calpe por retener a una mujer rumana».

Asimismo, las mujeres nigerianas, rumanas y marroquíes aparecen en noticias vinculadas con la negación de la nacionalidad española o el asilo. Puede ser que estas nacionalidades coincidan con aquéllas que tengan más obstáculos a la hora de conseguir la ciudadanía española. Esto puede estar vinculado con el hecho de que son percibidas por parte de la opinión pública española como las que presentan mayores dificultades para su integración en nuestro país, apelando a las diferencias culturales, religiosas o idiomáticas. Estas noticias no ayudan a que se tenga una imagen diferente de ellas y a lograr una mejor integración en nuestra sociedad.

Titular de El Mundo, 4-11-2004: «Deniegan la nacionalidad a una marroquí por no hablar castellano».

Titular de El Mundo, 5-03-2004: «Interior deniega el asilo a una nigeriana que fue mutilada».

\subsection{Los roles de la mujer inmigrante}

A partir del análisis anterior sobre la temática de las noticias, también podemos examinar los principales roles que la mujer inmigrante ejerce en la prensa nacional. De este modo, el rol principal que desempeña la mujer inmigrante en prensa es el de víctima: víctimas de redes ilegales o mafias que les obligan a ejercer la prostitución, víctimas de violencia por parte de su pareja o ex pareja sentimental, víctimas por abuso de autoridad, víctimas de violación, etc.

Titular de El Mundo, 6-11-2004: «Prisión e inhabilitación para un policía de extranjería por abusar de mujeres "sin papeles"».

Titular de $A B C$, 6-10-2004: «Ingresa en prisión el magrebí detenido por degollar a su novia ecuatoriana».

Titular de El Mundo, 8-02-2004: «Apalean a una mujer por no querer prostituirse». Subtítulo: «La policía detiene en Murcia a 19 miembros de una red de explotación a inmigrantes rumanas»? .

Un segundo rol que ejerce la mujer inmigrante en prensa es el de agresora o delincuente. Sobre todo, son madames que controlan a las mujeres prosti-

9. En esta noticia, aparecen seis fotografías del estado en que quedó la mujer tras las palizas. 


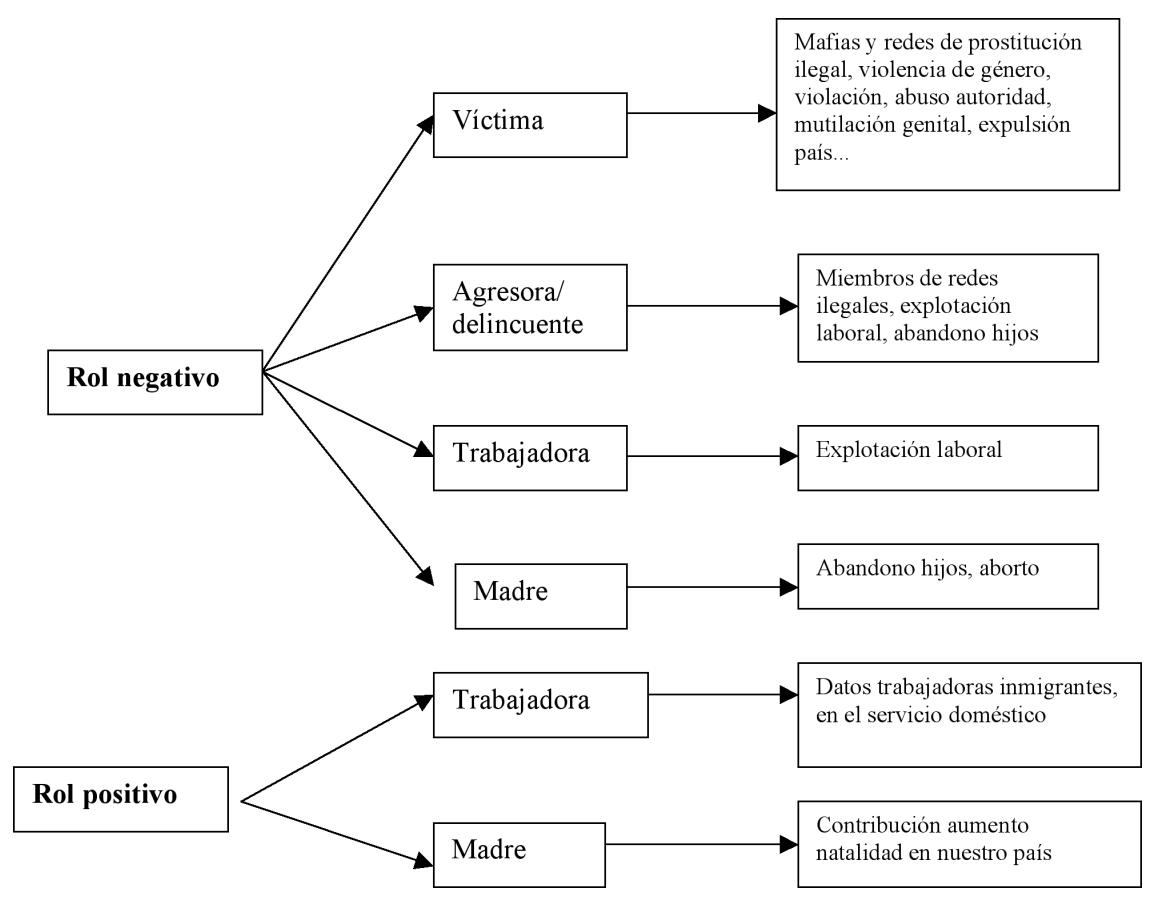

Figura 1. Roles que desempeña la mujer inmigrante en prensa

tuidas en los clubs o pisos. Asimismo, encontramos madres que abandonan a sus hijos. Un tercer y cuarto rol que ocupa la mujer inmigrante en la prensa nacional es el de trabajadora y el de madre, aunque éstos constituyen roles minoritarios respecto a los anteriormente mencionados.

En la figura 1 se visualizan los distintos roles que adopta la mujer inmigrante en la prensa clasificados según su carácter positivo o negativo, así como los temas en que aparecen relacionados cada uno de estos roles. Como podemos observar, el rol de «trabajadora» $\mathrm{y}$ «madre» puede adoptar un carácter positivo o negativo, según el tipo de noticia de que se trate. Los temas de explotación laboral por un lado, y el abandono de hijos y el aborto por otro, presentan a la mujer inmigrante con un rol de carácter negativo de trabajadora y madre, respectivamente (además de ejercer también el rol de agresora en este tipo de noticias). En cambio, las noticias sobre datos y/o informaciones de trabajadoras inmigrantes en el servicio doméstico y la contribución al aumento de la natalidad en nuestro país, ofrecen una imagen de la mujer inmigrante como trabajadora y madre desde un prisma positivo. En este sentido, uno de los pocos casos encontrados de noticias positivas sería la siguiente: 
Titular de El País, 29-06-2004: «La natalidad sigue en alza impulsada por las madres inmigrantes».

A la luz de estas evidencias, lo que echamos en falta son noticias positivas sobre aspectos de integración social, convivencia con la población autóctona, derechos sociales, beneficios que aporta a la sociedad de destino en términos económicos, culturales y sociales o sus logros personales y/o profesionales. No se hace mención a su trayectoria migratoria (condiciones del país de origen, a las razones por las que dejaron su país y se establecieron en el nuestro...) y, una vez en España, tampoco aluden a la vida cotidiana de estas mujeres, de cómo viven y cómo trabajan, de sus problemas y dificultades, de sus deseos y expectativas... Por este motivo, consideramos que se crea una imagen muy poco conveniente para la integración de estas mujeres en nuestra sociedad.

\section{5. ¿La mujer inmigrante como protagonista de la noticia? Un análisis de los titulares}

A través del análisis de los titulares hemos podido examinar el tipo de protagonismo de la mujer inmigrante en la noticia y el tipo de noticias en que aparece como actor principal. Los titulares, como presentación de la noticia, son la parte que sirve para enganchar o no al lector. Tal y como señalan Penalva y Mateo (2000: 189), «la primera imagen que se recibe en el titular es, muchas veces, la que permanece incluso tras la lectura del texto completo».

Desde nuestro punto de vista, no tiene el mismo valor que una mujer sea la protagonista en el cuerpo de la noticia o que simplemente forme parte de ella y sea otra persona la protagonista principal en el titular, por ejemplo:

Titular de El Mundo, 15-01-2004: «El primer bebé del año ya mendiga».

En este titular se ha puesto el énfasis en el niño, quizás por el carácter sensacionalista que tiene este tipo de noticias. Sin embargo, cuando se desarrolla la noticia, toda la información se centra en la madre. Se explica su situación económica y legal en nuestro país y, además, aparecen varias fotos de la mujer con el niño. En esta noticia se aprecia cómo el sensacionalismo desempeña un papel primordial en el titular.

Existen otros ejemplos en los que consideramos que la mujer no es la protagonista de la noticia debido al enfoque que se le da al titular, aunque después sea la protagonista en el cuerpo de la noticia:

Titular de $A B C, 4-2-2004$ : «Detenido un nigeriano por la muerte de su novia, que cayó de un cuarto piso».

Titular de El País, 13-06-2004: «Detenidos dos hombres por lanzar a una mujer por el balcón».

Titular de El Mundo, 22-02-2004: «Detenidos cuatro rumanos por obligar a mujeres a prostituirse». 
Titular de $A B C, 24-12-2004:$ «Cuatro detenidos por prostituir a menores rumanas en Castellón».

Observamos que este tipo de noticias es una fórmula que se repite con frecuencia en la prensa. Podemos afirmar que, cuando se trata de temas relacionados con la prostitución y el tráfico de seres humanos o en los casos de mujeres maltratadas y asesinadas por sus parejas, el titular se centra en las personas detenidas o en los agresores, aunque después se hable de la víctima o las víctimas. De este modo, en este tipo de noticias en las cuales los delincuentes son hombres y las víctimas mujeres, el titular pone su foco de atención en el delincuente, el hombre. Por otro lado, en el caso de las noticias en las que la mujer ejerce de delincuente o agresora, ésta aparece como protagonista:

Titular de El Mundo, 13-07-2004: «Detenida una mujer por agredir a su pareja con un cuchillo».

Titular de El Mundo, 18-04-2004: «Dos detenidas por explotar a 23 chinos».

Titular de $A B C, 18-09-2004:$ «Una mujer abandona a su bebé y deja una nota de disculpa».

Del mismo modo, la mujer también aparece como actor principal en otras ocasiones en las que no tiene el papel de víctima ni de agresora y, por tanto, no son noticias de suceso. Se trata de las noticias en las que se da algún tipo de información objetiva sobre algún aspecto relacionado con esta realidad en nuestro país:

Titular de $A B C, 11-11-2004:$ :Las mujeres inmigrantes superan ya a los hombres».

Titular de El Mundo, 28-11-2004: «Las jóvenes rumanas y ecuatorianas superan ya a las españolas en consultas para abortar».

Titular de El País, 29-06-2004: «La natalidad sigue en alza impulsada por las madres inmigrantes».

En estos casos anteriores, llama la atención la utilización de la palabra superan en varias noticias. Pensamos que es significativo que las mujeres inmigrantes superen a las españolas en algún aspecto de la vida social o que superen a los hombres inmigrantes en número. El uso repetitivo de esta palabra puede estar indicando una realidad en nuestro país que quieran transmitir los periódicos: la importancia cada vez mayor de las mujeres inmigrantes en la sociedad española. Opinamos que es un tratamiento positivo porque refleja la creciente feminización de la inmigración en nuestro país.

Por tanto, podemos decir que existen dos tipos de titulares, uno en el que la mujer aparece como protagonista y otro en el que es secundaria. Se da esta condición de secundaria cuando es víctima de la violencia por parte de un hombre (su compañero sentimental) o de organizaciones que la extorsionan (aunque hay algunas excepciones). Por otro lado, actúa como protagonista 
cuando es ella la agresora/delincuente o cuando son temas que las atañe principalmente a ellas (datos de natalidad, aborto, trabajo, etc.). La mujer inmigrante, por tanto, generalmente no realiza la acción, sino que es objeto de la acción del hombre. El hombre inmigrante es el actor principal de una acción casi siempre ruin y negativa. Con este hecho, se refuerza la imagen negativa de los inmigrantes en general.

\section{Conclusiones}

Desde las ciencias sociales, se insiste en la invisibilidad de las mujeres inmigrantes por su doble condición de mujer y extranjera. Esta invisibilidad sobre todo está estrechamente relacionada con el tipo de trabajo que realizan en nuestra sociedad, circunscrito a la esfera privada de la familia. Como hemos visto a lo largo del trabajo, la invisibilidad de las mujeres inmigrantes se hace patente en la prensa escrita, donde el hombre inmigrante ejerce mayor protagonismo. Imagen que no se corresponde con la importancia cada vez mayor del flujo migratorio femenino en nuestro país. Además de la escasez de noticias sobre la mujer inmigrante, hay algunas nacionalidades más representadas que otras, con lo que se facilita una percepción errónea de la inmigración femenina en nuestro país.

No cabe duda que las representaciones sociales de la mujer inmigrante por parte de la prensa nacional se alejan de la realidad social en la que viven estas mujeres en nuestro país. Sólo se proyecta la realidad de un colectivo específico de mujeres, puesto que se muestra básicamente el tipo de migración más marginal. En este sentido, nos remitimos a A. M. Bañón (2002), quien sostiene que se debe tener en cuenta no sólo lo que se dice, sino también lo que se omite. De este modo, se obvia que muchas de ellas son protagonistas del hecho migratorio y tienen un proyecto migratorio autónomo. Además, el trabajo doméstico que realizan las mujeres inmigrantes es casi inexistente en las noticias, con lo que se da mayor visibilidad a las mujeres que trabajan en la prostitución.

La prensa también ofrece una imagen de vulnerabilidad de la mujer inmigrante asociada al papel de víctima. Esta imagen estereotipada de la mujer inmigrante procede del imaginario social adscrito a la mujer oriunda de países pobres: dependiente, subordinada, víctima, sumisa, ignorante, perdida... Cabe apuntar que esta representación de la mujer inmigrante en la prensa escrita, es coherente con la imagen que los medios de comunicación en general ofrecen de sus países de origen en las noticias internacionales.

Con esto no estamos diciendo que no se deban relatar este tipo de noticias, sino que también existen otros temas que no aparecen en ningún momento y que podrían contribuir a dar una imagen más positiva y real de la mujer inmigrante. Por ejemplo, se podría aludir a la situación y a las condiciones de origen de estas mujeres; mencionar lo que aportan a la sociedad de acogida en términos económicos, sociodemográficos o culturales; hacer referencia a los motivos que llevan a estas personas a emigrar, a sus proyectos migratorios y a 
sus deseos y a sus expectativas ligados al proceso migratorio. En definitiva, sería necesario reflejar la inmigración como un proceso social y humano.

\section{Referencias bibliográficas}

ABELla, C. M. (2002). «La construcción de la inmigración como problema en la prensa escrita». Sociedad y Utopia, no 19, p. 61-80.

Álamo, M. del (1997). Migraciones: realidades y tópicos en los Medios de Comunicación escritos. Valencia: Nau Llibres/CC.OO./CITMI-CITE.

ARgote, R. (2003). «La mujer inmigrante en el cine español del inaugurado siglo XXI». Feminismo/s, revista del Centro de Estudios sobre la Mujer de la Universidad de Alicante, no 2, p. 121-138.

Aubarell, G. (2000). «Una propuesta de recorrido bibliográfico por las migraciones femeninas en España». Papers, no 60, p. 391-413.

Bañón, A. M. (2002). Discursos e inmigración. Propuestas para el análisis de un debate social. Murcia: Universidad de Murcia.

Bodas, J.; Dragoevich, A. (eds.) (1994). El Mundo árabe y su imagen en los medios. Madrid: Comunica.

BONELli, E.; UlLOA, M. (coord.) (2001). Tráfico e inmigración de mujeres en España: colombianas y ecuatorianas en los servicios domésticos y sexuales. Madrid: ACSURLas Segovias.

BuISEF, D. (1994). «Medios de comunicación y visiones del Magreb. La percepción Norte-Sur en la prensa española». Voces y Culturas, no 6, p. 11-21.

Calvo, F. (2001). «Apuntes para un análisis de prensa». En: BONELli, E.; UlloA, M. Tráfico e inmigración de mujeres en España. Colombianas y ecuatorianas en los servicios domésticos y sexuales. Madrid: ACSUR-Las Segovias, p. 51-64.

CARMONA, S. (2000). "Inmigración y prostitución: el caso del Raval (Barcelona)». Papers, no 60, p. 343-354.

CATARINA, C.; Oso, L. (2000). «La inmigración femenina en Madrid y Lisboa: hacia una etnización del servicio doméstico y de las empresas de limpieza». Papers, $\mathrm{n}^{\circ}$ 60, p. 183-207.

Colectivo IoÉ (1991a). El servicio doméstico en España. Entre el trabajo invisible y la economía sumergida. Madrid: JOCE.

- (1991b). Trabajadoras extranjeras de servicio doméstico en Madrid. Ginebra: Oficina Internacional del Trabajo (OIT).

- (2001). Mujer, inmigración y trabajo. Madrid: Ministerio de Trabajo y Asuntos Sociales. Instituto de Migraciones y Servicios Sociales (IMSERSO).

CONSEJO ECONOMICO Y SOCIAL (CES) (2004). Informe sobre la migración y el mercado de trabajo en España, disponible en: <http://www.ces.es>.

ESCRIVÁ, M. Á. (2000). «¿Empleadas de por vida? Peruanas en el servicio doméstico de Barcelona». Papers, no 60, p. 327-342.

EsCRIVÁ, M. Á.; ROMERO, B. (1997). Se busca trabajo: fija, interina, por horas. Barcelona: ASOMIPEX.

ESTUPIÑÁN, L. M. (1997): «Las minorías culturales en los medios de comunicación españoles». Mugak, no 2, p. 37-41.

GonZÁlez, Ma J. y otros (2004). Sociología de la Comunicación. Alicante: Librería Compás. 
Instituto Nacional de Estadística (INE) (2004). Padrón municipal de habitantes, disponible en: <http://www.ine.es/>.

IZQUIERDO, A. (dir.) (1996). Panorámica general de la inmigración femenina en España $y$ los efectos del proceso migratorio sobre el rol y el estatus socio-económico de las trabajadoras extranjeras en España. Informe inédito de investigación. Madrid: Instituto de la Mujer.

LORITE, N. (2004). «Como miran los medios la inmigración y transmiten la diversidad», ponencia presentada en el diálogo Comunicación y diversidad cultural, del Forum Universal de las Culturas, Barcelona.

MarTínez, U. (1995). Mujer, trabajo y domicilio: los orígenes de la discriminación. Barcelona: Icaria.

MCCOMBS, M.; EvaTT, D. (1995). «Los temas y los aspectos: explorando una nueva dimensión de la agenda setting». Comunicación y Sociedad, vol. VIII, no 1, p. 7-32.

Ministerio de Trabajo y Asuntos Sociales (2004). Anuario de Estadísticas Laborales, disponible en: <http://www.mtas.es>.

Oso, L. (1998). La inmigración hacia España de las mujeres jefas del hogar. Madrid: IMU.

Parella, S. (2000). «El trasvase de desigualdades de clase y etnia entre mujeres: los servicios de proximidad». Papers, no 60, p. 275-289.

- (2003). Mujer, inmigrante y trabajadora: la triple discriminación. Barcelona: Anthropos.

Penalva, C.; Mateo, M. A. (2000). «Análisis narrativo y guerra. La cobertura del diario El Pais sobre el conflicto de Kosovo». Revista Internacional de Sociología, no 26, p. $187-210$.

PeÑAmarín, Cristina (1997). «El análisis de textos en una clave. Discursos e imágenes sobre la inmigración en El País». Cuadernos de Información y Comunicación, octubre-diciembre (3), p. 145-154.

PÉREZ, C. (2003). «Las inmigrantes en la prensa: víctimas sin proyecto migratorio». Mugak, no 24, tercer trimestre, disponible en: <http://www.pensamientocritico.org>.

Rizo, M. (2001). «Miedo y compasión: dos estrategias de movilización afectiva en el discurso informativo sobre el inmigrante». Comunica, no 2, disponible en: $<$ http://www.aijic.com/comunica/comunica2/comunica2.htm>.

Rodrigo, M.; MARTíneZ, M. (1997). «Minories étniques i premsa europea d'èlit». Anàlisi, no20, p. 13-36.

RoIZ, M. (1994). «La construcción de la diferencia cultural de los inmigrantes en los medios de información». Documentación Social, no 97, p. 177-197.

SiURANA, J. C. (2004). La inmigración en la prensa valenciana. Análisis ético. Valencia: CeiM.

SOLÉ, C. (1994). La mujer inmigrante. Madrid: Instituto de la Mujer.

TAYLOR, S. J.; BODGAN, R. (1992). Introducción a los métodos cualitativos de investigación. Barcelona: Paidós.

VAN DijK, Teun A. (1997): «Análisis crítico de las noticias», en Racismo y análisis crítico de los medios. Barcelona: Paidós. 